\title{
A unidade e a diversidade no ensino de Língua Portuguesa
}

\section{The unity and the diversity in the Portuguese language teaching}

Silvia Rodrigues Vieira ${ }^{1}$

Resumo: Considerando a abordagem da unidade e da diversidade no ensino da Língua Portuguesa, o presente artigo destaca duas prioridades: de um lado, a sistematização do comportamento de variedades consoante o continuum compósito fala-escrita e monitoração estilística; de outro, o desenvolvimento de metodologias para a abordagem das regras variáveis em sala de aula. Quanto ao referido continuum, propõe o mapeamento de fenômenos morfossintáticos em diversos gêneros da fala e da escrita contemporâneas, detalhando o comportamento da alternância "ter-haver" existenciais. Trata-se de mapeamento fundamental para que as orientações didáticas quanto ao uso da língua reflitam as variedades efetivamente praticadas pelos falantes cultos do Português. No que se refere ao desenvolvimento de metodologias, com base na proposta de "três eixos para o ensino de gramática", indicam-se trabalhos que demonstram ser possível a ampliação do repertório dos alunos em termos de variação e normas, seja no âmbito da produção, seja no da recepção/leitura.

Palavras-chave: Língua Portuguesa; Variação; Ensino; Continua; Norma.

Abstract: Considering the approach of unity and diversity in Portuguese language teaching, this article highlights two priorities: on the one hand, the systematization of linguistic varieties according to the composite continuum of speech-writing plus stylistic monitoring; on the other hand, the development of pedagogical methodologies to approach variable rules. As for the continuum, it proposes the mapping of morphosyntactic phenomena in several oral and written textual genres, detailing the variable behavior of existential "ter-haver". It is assumed that the didactic orientations regarding the use of the language must reflect the varieties effectively practiced by the educated speakers of Portuguese. Regarding the development of methodologies, based on the proposed "three axes for grammar teaching", we indicate works that show that it is possible to expand the repertoire of students in terms of variation and norms, be it in the scope of production, or in the reception / reading room.

Keywords: Portuguese language; Variation; Teaching; Continua; Norm.

1 Professora Associada III e Pesquisadora do Programa de Pós-graduação em Letras Vernáculas e do Mestrado Profissional em Letras - UFRJ. E-mail: silviavieira@hotmail.com 


\section{Introdução}

Honrando a temática eleita para o VIII Encontro de Sociolinguística - Variação e ensino: unidade e diversidade -, o presente artigo ocupa-se do tratamento de um ponto fundamental nas salas de aula de Português no país: a questão da(s) norma(s) linguística(s). Embora o tema há muito ocupe a agenda de educadores e linguistas, ele permanece atual e ainda necessitando de atenção nos planos teórico e metodológico.

A fim de contribuir com o tratamento do tema, pretende-se, em alguma medida, apresentar caminhos para avançar no conhecimento e na abordagem didático-pedagógica da norma-padrão (esfera do que é considerado modelar/idealizado) e das normas de uso (esfera do que é praticado/concretizado). Cumprindo tal propósito, o texto, primeiramente, sintetiza os fundamentos usualmente adotados quanto ao ensino de gramática, variação e normas, propondo diretrizes para o contexto didático-pedagógico. Em segundo lugar, apresenta duas frentes de trabalho para que o ensino de Português reflita os avanços científicos da área, relacionadas, de um lado, à atualização teórico-descritiva e, de outro, a propostas metodológicas para a abordagem dos temas variáveis em sala de aula.

\section{Fundamentos para o ensino: concepções de gramática, variação e norma(s)}

A respeito das concepções básicas que fundamentam o ensino de Língua Portuguesa, é fundamental contextualizar as orientações que acabam por definir o trabalho com a unidade e a diversidade linguísticas em sala de aula. Nesse sentido, buscamos responder a duas perguntas: (i) o que dizem as orientações oficiais em relação ao objeto do ensino de Português e a seus objetivos? e (ii) o que dizem os cientistas?

Para responder à primeira dessas questões, tomamos por base os Parâmetros Curriculares Nacionais (PCN), dado o relevante papel que desempenharam na redefinição dos rumos da área, e a Base Comum Curricular Nacional (BCCN), que acaba por constituir, no momento atual, uma espécie de objetivação de muitas das orientações dos Parâmetros.

De forma bem sintética, pode-se afirmar que os PCN (BRASIL, 1998) propõem que a "linguagem" seja concebida como atividade discursiva e, assim sendo, desenvolver a competência discursiva, tomando como objeto de ensino o texto, em sua diversidade de gêneros (orais e escritos), deva ser o objetivo maior das aulas de Língua Portuguesa. Nesse sentido, o ensino gramatical deve estar totalmente articulado às práticas da linguagem. A metalinguagem figura como instrumento de apoio para a reflexão sobre os fenômenos linguísticos, integrando, assim, a recomendada tríade: uso-reflexão-uso. No âmbito dessa reflexão, o documento propõe destaque aos temas da variação linguística e do combate ao preconceito. É nesse contexto do tratamento da variação que os PCN advogam que é papel do ensino de Língua Portuguesa a promoção das chamadas normas urbanas de prestígio, especialmente na modalidade escrita.

A Base Comum Curricular Nacional, além de reafirmar esses fundamentos, propõe que o trabalho com as séries do Ensino Fundamental se organize de modo a contemplar quatro eixos de habilidades e conteúdos: (i) oralidade; (ii) leitura/escuta; (iii) produção (escrita e multissemiótica); e (iv) análise 
linguística/semiótica. Segundo o documento, este último envolve "conhecimentos linguísticos - sobre o sistema de escrita, o sistema da língua e a norma-padrão -, textuais, discursivos e sobre os modos de organização e os elementos de outras semioses." (BRASIL, 2018, p.67).

Dada a abrangência do que se identifica como "conhecimento linguístico" e o detalhamento que se encontra na BNCC - que estabelece, por campo de conhecimento, objetivos e conteúdos específicos para cada série escolar -, é inegável que integra a proposta o trabalho com a gramática no que tange tanto à unidade (o que fortemente se coaduna com a noção de "sistema" e de "norma-padrão"), quanto à diversidade (o que se associa ao conjunto de variedades/normas que respaldam a própria concepção de padronização).

Do ponto de vista teórico, há de se ressaltar certas convergências entre os pressupostos admitidos por linguistas e os propostos nas orientações ora resumidas. Vieira e Brandão (2007) - para citar apenas uma obra -, por exemplo, admitem como pressupostos para o ensino de Língua Portuguesa:

(1) O objetivo maior do ensino de Língua Portuguesa é desenvolver a competência de leitura e produção de textos.

(2) A unidade textual - em toda a sua diversidade de tipos e gêneros, nos diferentes registros, variedades, modalidades, consoante as possíveis situações sócio-comunicativas - deve ser o ponto de partida e de chegada das aulas de Português.

(3) Os elementos de natureza formal - relativos aos diferentes níveis da gramática - são essenciais para a construção do texto. (VIEIRA; BRANDÃO, 2007, p.56)

Na realidade, é a orientação que se dá em termos metodológicos ao terceiro desses pressupostos que mais tem causado diferenças nas abordagens, sobretudo em termos metodológicos. Vieira (2014, 2017a, 2017b, 2017c) tem insistido, em continuidade ao desenvolvimento dos pressupostos ora apresentados, que os elementos pertinentes aos diferentes níveis da gramática precisam ser explicitamente trabalhados - por meio de atividades não só linguísticas, mas também epilinguísticas (cf. FRANCHI, 1998) - como objeto do ensino, e devem ser sistematizados - por meio de atividades metalinguísticas - na medida e no momento oportunos e adequados ao alunado. Trata-se do que a autora sistematiza como um dos "três eixos para o ensino de gramática", com base nos quais três questões devem orientar o trabalho pedagógico com os temas linguísticos:

(i) que elementos/conceitos em termos teórico-descritivos devem ser do domínio do aluno para que o tratamento do tema gramatical seja bem trabalhado? [Eixo I: Gramática e atividade reflexiva];

(ii) qual a relação entre esse tema gramatical e a produção de sentidos no nível textual (leitura ou produção)? [Eixo II: Gramática e produção de sentidos];

(iii) como esse tema se relaciona ao domínio de normas frente à realidade da variação linguística? [Eixo III: Gramática e normas/variedades].

É nesse contexto que se situa a temática central do presente texto, a da(s) norma(s) linguística(s) no ensino de Língua Portuguesa. Com base nos fundamentos ora brevemente apresentados, há de se defender que a sala de aula deve ter espaço tanto para a unidade do sistema e, em alguma medida, da padronização, quanto para a produtiva diversidade de expressões/variedades do que se costuma identificar 
como Português do Brasil. É, portanto, nos desafios dos Eixos I e III, que alia reflexão gramatical ao tratamento da variação linguística, e sem deixar de contemplar a contextualização dos fenômenos variáveis nos gêneros textuais, no âmbito do Eixo II, que se pretende, aqui, tratar o comportamento de regras variáveis e das noções gramaticais necessárias à compreensão das formas alternantes em questão.

No que se refere ao domínio de variedades/normas de uso, mantemos, aqui, os pressupostos assumidos anteriormente:

\begin{abstract}
Cabe aos sociolinguistas descrever as estruturas que pertencem às normas/variedades cultas, na língua oral e na escrita brasileiras, de modo a permitir que se avalie a proximidade ou a distância dessas normas em relação (i) a outras normas já dominadas pelos estudantes quando chegam à escola (as normas vernaculares); e (ii) a outras normas que se apresentam nos diversos gêneros textuais trabalhados nas aulas de Português, que lidam com materiais da sincronia atual e até de outras sincronias. (VIEIRA; FREIRE, 2014, p. 84)
\end{abstract}

Cabe advertir, a respeito da tarefa da Sociolinguística, que a promoção do conhecimento das variedades/normas cultas deve ser entendida de forma particularizada em relação aos campos da produção e da recepção/percepção linguísticas. Nesse sentido, os campos da leitura/escuta e da produção escrita eixos da BNCC - têm íntima relação com a proposta ora destacada.

As atividades de leitura considerando diversos gêneros textuais, conforme detalha Vieira (2013), constituem oportunidade de atestar não só as variantes cultas - formas efetivamente usadas na fala e na escrita contemporâneas de indivíduos escolarizados em situações diversas -, mas também variantes utilizadas apenas em determinadas práticas sociais, configurando particularidades e até tradições discursivas. Um trabalho reflexivo sobre os usos das variantes em gêneros diversos, desta e de outras sincronias, permitirá, assim, avaliar o que muitas vezes os livros didáticos e até professores apresentam aos alunos como "norma culta", que, via de regra, mescla estruturas vernaculares gerais, estruturas apenas dos gêneros escritos cultos, e, ainda, estruturas em flagrante desuso mas circunscritas a sincronias passadas ou a tradições discursivas. Trata-se da idealização das formas tidas como corretas e modelares no conjunto que tecnicamente deveria ser identificado como um dos modelos de "norma-padrão", e não efetivamente de "norma culta" (cf. FARACO, 2008; FARACO; ZILLES, 2017).

Nesse sentido, dentro do propósito de promoção do domínio de normas de prestígio, têm lugar na escola tanto variantes que figuram em gêneros corriqueiros (notícias e crônicas de jornais, por exemplo) como formas em desuso no PB contemporâneo, mas registrados, por exemplo, nos livros didáticos em gêneros do domínio literário (poemas, contos e romances) ou até em gêneros particulares mas socialmente produtivos, como os do domínio religioso. Uma breve incursão em um manual de Língua Portuguesa do Ensino Médio permitirá observar estruturas que vão da brasileira próclise em início absoluto, em uma tirinha ou um anúncio publicitário, até uma forma contrata de clíticos (como a que ocorre no poema de Almeida Garret, em "Este inferno de amar - como eu amo! Quem mo pôs aqui n'alma... quem foi?"), ou o uso do paradigma de segunda pessoa do plural (como no fragmento do "Sermão a Santo Antônio (Sermão aos peixes)", de Padre Vieira, em "Antes, porém, que vos vades, assim como ouvistes os vossos louvores, ouvi também agora as vossas repreensões."). ${ }^{2}$

2 Para detalhamento da relação entre leitura, gêneros textuais e uso de variantes linguísticas cultas, consultar Vieira (2013) e Vieira e Freire (2014). 
É fundamental, portanto, que se delimite o que os documentos propõem como "ensinar norma culta" ou "promover o domínio de normas urbanas de prestígio" em duas frentes de trabalho: (i) definir as formas alternantes de cada regra variável que devem ser ativadas/compreendidas no processo de leitura/escrita, mas que raramente serão objeto de produção - a não ser que se trate do desenvolvimento de habilidades literárias ou específicas a um campo do saber, como o jurídico, religioso, dentre outros -; e (ii) definir as formas alternantes de cada regra variável que são produtivamente ativadas no processo de produção de textos, consoante sua distribuição em contínuos de fala-escrita e monitoração estilística. Dessa forma, entendemos ser possível desenvolver o conhecimento da variação linguística interna às variedades cultas. Em outras palavras, o conhecimento sociolinguístico permite demonstrar que norma culta não é norma-padrão (que, respeitado o pressuposto da variação, também deve ser objeto de sistematização escolar); norma culta não constitui um bloco homogêneo; norma culta é variável, é plural; o que se entende tecnicamente por norma culta é um conjunto de variedades que se distribuem na fala e na escrita.

\section{Para a abordagem produtiva da unidade e da variedade}

Com base nos pressupostos sintetizados na seção anterior, parece urgente desenvolver, no campo dos estudos linguísticos voltados ao que se pode identificar como Sociolinguística Educacional (BORTONIRICARDO, 2005) ou Pedagogia da variação linguística (FARACO, 2008; ZILLES; FARACO, 2015), duas prioridades: (a) na esfera teórico-descritiva, atualização e sistematização de resultados para propor o trabalho com variedades cultas no continuum fala-escrita; e (b) na esfera de caráter aplicado, o desenvolvimento de metodologias que permitam lidar produtivamente com essas variedades.

a) Normas de uso e adequação descritivo-explicativa

Grande esforço tem sido feito por sociolinguistas brasileiros, sobretudo os engajados no GT de Sociolinguística da ANPOLL, para oferecer à comunidade científica um mapeamento das variedades brasileiras, como comprova a produção recente de membros da equipe (Cf., por exemplo, MARTINS; VIEIRA; TAVARES, 2014; MARTINS; ABRAÇADO, 2014).

Mais especificamente voltados aos desafios do ensino de fatos morfossintáticos, Vieira e Freire (2014) dedicaram-se a sistematizar resultados científicos que dessem conta da variação interna à chamada "norma culta". Considerando diversos fenômenos - concordância verbal de $3^{a}$ pessoa, estratégias de indeterminação do sujeito, expressão do acusativo e do dativo anafóricos de terceira pessoa, colocação pronominal e alternância dos verbos existenciais "ter" e "haver" -, os autores propõem um continuum compósito de oralidade-letramento e monitoração estilística³. Vieira (2014), detalhando o comportamento dos gêneros textuais da escrita jornalística, demonstra a vitalidade desse continuum no caso específico da colocação pronominal. Assim, permite refletir sobre a variação estilística, a monitoração e a escrita culta brasileira. Recentemente, a autora (VIEIRA, 2017d) apresenta propósito semelhante examinando

\footnotetext{
3 Bortoni-Ricardo (2005) propõe três continua para a compreensão da complexidade das variedades do Português do Brasil, quais sejam: rural-urbano; oralidade-letramento e monitoração estilística.
} 
especificamente o caso das estratégias de relativização na fala e na escrita (jornalística) brasileira.

O conjunto dessas referências, dentre outras, demonstra a necessidade de uma sistematização dos usos cultos - ao lado de todas as variedades populares - em função de uma diversidade de gêneros textuais. Assumindo esse propósito como agenda de pesquisa, uma primeira experiência encontra-se em curso para esse mapeamento mais detalhado e planejado ${ }^{4}$. Trata-se de projeto inicial, intitulado Contínuos de/em variedades do Português: análises contrastivas, que visa a descrever variantes de diversos fenômenos morfossintáticos considerando gêneros de concepções de fala e de escrita, igualmente diversos. É dessa forma que se entende ser possível desenvolver orientações escolares, incluindo as de caráter avaliativo/"normativo", que efetivamente "reflitam a norma efetivamente praticada", conforme propõe Faraco $(2015, \mathrm{p} 8)$.

A título de ilustração, vale observar, neste artigo, a distribuição de dados de uma regra variável binária: a da alternância "ter"e "haver"com valor existencial ("tem muitas pessoas lá fora" versus "há muitas pessoas lá fora"). Com base nesse tema, é possível demonstrar a abrangência da proposta.

Avelar (2006) permite apresentar a distribuição de dados de fala e escrita - reunidas diversas expressões dessas modalidades - extraídos de pesquisas sobre o uso das construções existenciais da fala de indivíduos com curso superior (Corpus Nurc-RJ/década de 1990) e com escolaridade básica (Corpus PEUL/década de 1980), de um lado, e, de outro, da escrita de textos extraídos de jornais produzidos entre 2003 e 2005 (jornais cariocas O Globo e Extra), anúncios (revistas Veja, Isto é, Época e Super Interessante) e livros diversos. A tabela 1 permite observar a distribuição geral desses resultados:

Tabela 1: Alternância "ter"e "haver"na língua oral e na escrita com base em Avelar (2006)

\begin{tabular}{c|c|c}
\hline & Ter & Haver \\
\hline Fala & $87 \%$ & $13 \%$ \\
\hline Escrita & $14 \%$ & $86 \%$ \\
\hline
\end{tabular}

Como se pode observar, esse fenômeno revela preferências inversas quanto à variação por modalidade: enquanto a fala (inclusive a culta) adota preferencialmente o "ter" existencial, a escrita demonstra ampla preferência por "haver". O autor, dando continuidade a sua observação, demonstra ser essa distribuição sensível aos gêneros em questão, que certamente revelam maior ou menor atenção às variantes empregadas (maior monitoração), em função de maior ou menor compromisso com estruturas que supostamente seriam consideradas mais compatíveis com contextos de escrita formal. Assim, já se delineia que as variantes serão mais bem descritas se, além do continuum fala-escrita, for controlado o grau de monitoração estilística.

Sendo o controle da monitoração estilística exercício altamente complexo - visto que envolve não só as propriedades do gênero, mas também os participantes da interação, a audiência, a temática em

\footnotetext{
${ }^{4}$ Com base na experiência da disciplina Tópicos especiais do Programa de Pós-graduação em Letras Vernáculas/UFRJ, por mim ministrada em 2018-1, deu-se início ao Projeto Contínuos de/em variedades do Português: análises contrastivas. Nos trabalhos finais da referida disciplina, foram abordados, em dez gêneros textuais diferentes, sete temas variáveis: estratégias de indeterminação do sujeito; preenchimento do objeto direto anafórico de 3 a pessoa; preenchimento do dativo anafórico de 3 a pessoa; colocação pronominal; expressão verbal de futuro; alternância de "ter" e "haver" existenciais; estratégias de relativização. Um livro com resultados dessa experiência está em fase de elaboração; por ora, divulgam-se, neste artigo, apenas resultados parciais do levantamento de dados referente à alternância de "ter" e "haver" existenciais.
} 
questão, a situação contextual, o suporte, dentre outros elementos -, assume-se, aqui, ainda de forma limitada, apenas a observação do gênero textual como um dos quesitos para a compreensão dos usos cultos na modalidade escrita.

Se considerado novamente Avelar (2006), destacando de seus resultados apenas os dados retirados de piadas (do Casseta e Planeta), anúncios (de revistas impressas) e textos jornalísticos (de gêneros não detalhados pelo autor) extraídos do Jornal $O$ Globo, podemos observar, conforme mostra a tabela 2, a sensibilidade do fenômeno ao perfil de cada gênero.

Tabela 2: Alternância "ter" e "haver" em gêneros da modalidade escrita com base em Avelar (2006)

\begin{tabular}{c|c|c}
\hline Fontes da escrita & Ter & Haver \\
\hline piadas & $60 \%$ & $40 \%$ \\
\hline Anúncios & $47 \%$ & $53 \%$ \\
\hline textos de O Globo & $0 \%$ & $100 \%$ \\
\hline
\end{tabular}

Dispondo, ainda, os resultados que o autor apresenta para entrevistas sociolinguísticas e gêneros da escrita em um gráfico (cf. gráfico 1), é possível observar claramente o continuum de usos cultos consoante modalidade e, supostamente, grau de monitoração estilística.

Gráfico 1: Alternância "ter" e "haver" em gêneros da fala e da escrita segundo Avelar (2006)

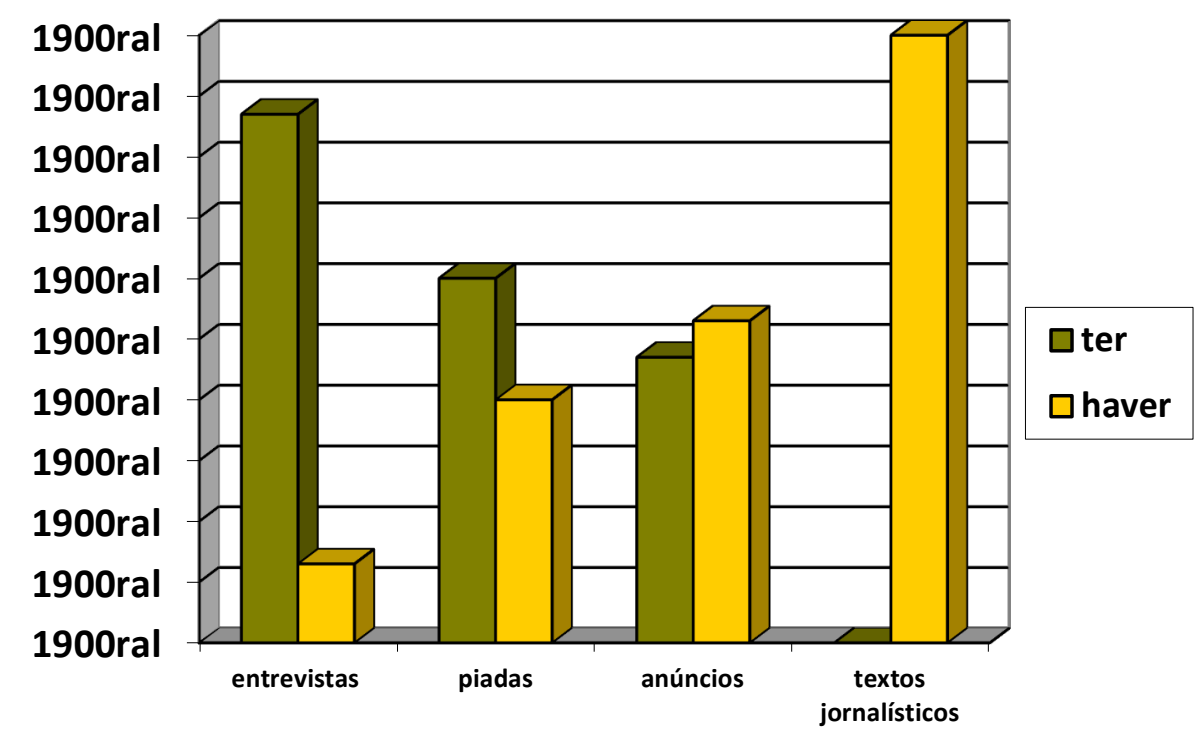


Considerando resultados a partir da coleta de dados contemporâneos, Gama, Saraiva e Almeida (2018) mapearam os usos cultos de "ter" e "haver" existenciais em diversos gêneros textuais, permitindo detalhar o continuum compósito fala-escrita e monitoração estilística ora proposto. Foram os seguintes os gêneros controlados pelas autoras: entrevistas sociolinguísticas ${ }^{5}$, tirinhas; anúncios; entrevistas (em jornais ou revistas); cartas de leitor, crônicas jornalísticas, notícias; editoriais; teses/dissertações e artigos em revistas científicas ${ }^{6}$.

Gráfico 2: Alternância "ter" e "haver" em gêneros da fala e da escrita, segundo Gama; Saraiva; Almeida

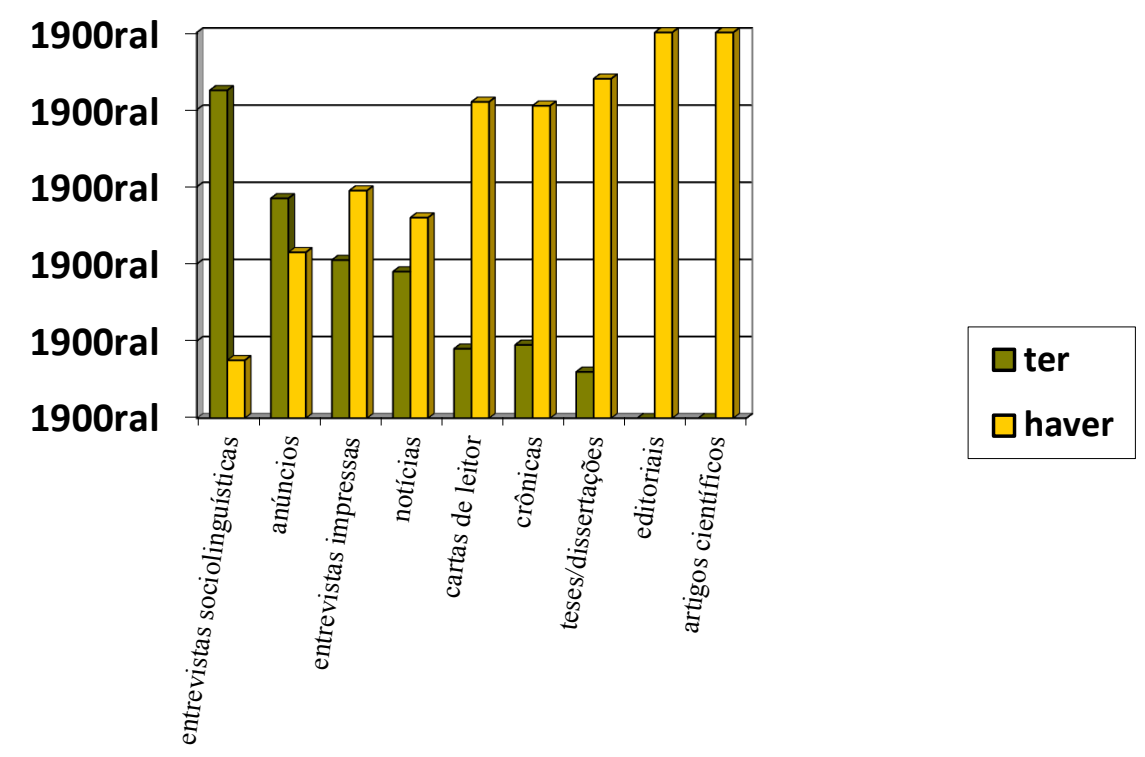

(2018)

\footnotetext{
${ }^{5}$ Conferir amostra do Rio de Janeiro do banco de dados Concordância do Projeto Estudo comparado dos padrões de concordância em variedades africanas, brasileiras e européias do Português. Disponível em www.corporaport.letras.ufrj.br.

${ }^{6}$ Embora não se tenham detalhado, nos limites deste artigo, as fontes para a composição do corpus, deve-se levar em consideração que os gêneros de jornal e revista foram extraídos, em sua maioria, de veículos de circulação pública, em sua maioria destinados à classe médiaalta e alta, como O Globo, Folha de São Paulo, Jornal do Brasil e, mais raramente, Extra. Os textos acadêmicos foram extraídos de bancos de tese e revistas acadêmicas da área de Comunicação Social, produzidos na Região Sudeste. Salienta-se, ainda, que os resultados referentes tirinhas não são dispostos no gráfico porque se referem a apenas duas ocorrências, o que impede qualquer generalização.
} 
Embora o conjunto dos resultados referentes à alternância "ter-haver" ora sintetizados advenha de trabalhos com objetivos e dados de naturezas diversificadas, e exatamente por isso, há de se destacar a evidente imagem de um crescente de mudança comportamental, que pode ser formulada da seguinte maneira: (i) quanto mais "oral" (leia-se concepção de oral, e não necessariamente meio físico oral), maior o uso de "ter"; quanto mais "escrito" for o texto, mais "haver"; e, paralelamente ou subjacente a isso, (ii) quanto menos controlada/monitorada a produção do texto (leia-se: supostamente maior controle no uso das variantes; , maior intenção de ser "formal", maior revisão textual), maior o uso de "ter" e, inversamente, quanto mais controlada/monitorada a produção do texto, maior o uso de "haver".

Essas considerações iniciais, tomando por base exclusivamente os dados quantitativos em questão, permitem supor senão um continuum muito rígido, ao menos três espaços dele constitutivos, que podem ser assim representados:

Figura 1: Continuum compósito fala-escrita e monitoração estilística: uso do "ter" existencial

\begin{tabular}{|c|c|c|}
\hline $\begin{array}{c}\text { [+ oral / - } \\
\text { monitorado] }\end{array}$ & & $\begin{array}{c}\text { [- oral / + } \\
\text { monitorado] }\end{array}$ \\
\hline $\begin{array}{l}\text { Entrevistas } \\
\text { sociolinguísticas } \\
\text { Piadas } \\
\text { Anúncios }\end{array}$ & $\begin{array}{l}\text { Entrevistas impressas } \\
\text { Cartas de leitor } \\
\text { Notícias } \\
\text { Crônicas }\end{array}$ & $\begin{array}{l}\text { Teses/dissertações } \\
\text { Artigos científicos } \\
\text { Editoriais }\end{array}$ \\
\hline $47-83 \%$ & $19-41 \%$ & $0-12 \%^{7}$ \\
\hline
\end{tabular}

Fonte: elaborado pela autora.

Perseguindo o propósito de fundamentar as orientações pedagógicas que tomem por base efetivamente as normas/variedades cultas praticadas, é fundamental que se ofereça, à semelhança das referências citadas e do que se apresentou quanto à alternância "ter-haver" existenciais, o tratamento de diversos fenômenos morfossintáticos em diferentes gêneros textuais para testar a abrangência do continuum proposto.

b) Propostas metodológicas: sequências de atividades

Conforme anunciado, uma segunda prioridade para a área da Sociolinguística Educacional ou para o desenvolvimento de uma Pedagogia da variação linguística deve assumir caráter aplicado, de modo que se elaborem, experimentem, avaliem e reelaborem atividades e metodologias que permitam lidar produtivamente com as regras variáveis e, consequentemente, com as variedades.

Nesse campo de atuação, vale divulgar os diversos trabalhos que vêm sendo orientados no Mestrado Profissional em Letras (PROFLETRAS), bem como no âmbito de outros programas e instituições. Em função de limites óbvios do presente artigo, limitamo-nos a citar, exclusivamente, a proposta de alguns trabalhos que contemplam os três eixos para o ensino de gramática (Cf. VIEIRA, 2014; 2017a, b, c; 2018),

\footnotetext{
7 No extremo de letramento/escritura, deve-se salientar que os poucos dados de "ter" registrados também se diferenciam qualitativamente, visto que muitos dos exemplos são da estrutura "tem-se", em vez de simplesmente "tem".
} 
descritos anteriormente no presente artigo. Cada proposta didático-pedagógica em questão (estudo dirigido, sequência de atividades, dentre outros) procura dar conta (i) do conhecimento que deve ser construído (linguística e epilinguisticamente) e sistematizado (metalinguisticamente) quanto ao recurso gramatical em foco; (ii) da relação desse recurso com a produção de sentidos nos gêneros textuais em que aparece; e (iii) do comportamento do tema no sistema linguístico como regra variável, se for o caso.

A título de divulgação, cabe registrar alguns temas já abordados sob nossa orientação na perspectiva dos três eixos para o ensino de gramática: (i) indeterminação do sujeito, por Souza (2015); (ii) expressão de segunda pessoa discursiva, por Gouvêa (2016); concordância verbal de $3^{3}$ pessoa, por Chagas (2016); expressão verbal de futuro, por Durval (2017); quadro pronominal, por Lima (2017); e colocação pronominal, por Almeida (2018)

Em linhas gerais, pode-se destacar que todos os trabalhos priorizam o tratamento de um recurso gramatical. Partindo do pressuposto de que todo e qualquer recurso gera sentidos na língua em uso, todas as propostas desenvolvem atividades específicas das unidades gramaticais em que os recursos se localizam (se for a oração, a oração é explorada particularmente em certas atividades; se for o vocábulo, a unidade vocabular é explorada particularmente ${ }^{9}$ ), sem deixar de contemplar atividades de leitura e produção textual. É importante destacar que o trabalho com a indeterminação do sujeito, com o uso da segunda pessoa discursiva, com a referenciação pronominal, apenas para citar alguns exemplos, permite abordar o efeito semântico-discursivo da construção gramatical até no nível da macroestrutura textual, fato que não se verifica, ao menos nos mesmos termos, no caso da concordância verbal ou da colocação pronominal, por exemplo, fenômenos que estabelecem sentidos de natureza microestrutural (ou, no máximo, externa à língua, se considerado o valor indexical das variantes).

Algumas propostas privilegiam certos gêneros textuais, tendo em vista que determinados fenômenos (nem todos) tomam feições particulares ou são mais produtivos em determinadas situações sociocomunicativas. Entretanto, cabe ressaltar que, para que o cumprimento do terceiro eixo do ensino de gramática (o da variação linguística) efetivamente ocorra, é necessário, como ficou evidente nos resultados da alternância "ter-haver" no continuum desenvolvido na subseção anterior deste texto, que se aborde uma diversidade de gêneros em comparação, para que a pluralidade de normas em uso seja efetivamente trabalhada.

\section{Considerações finais}

Espera-se que o presente artigo tenha colaborado no sentido de demonstrar que o avanço científico no campo dos estudos linguísticos constitui forte aliado da área pedagógica no que se refere à abordagem da unidade e da diversidade na língua. Nesse sentido, duas prioridades foram destacadas no presente artigo:

\footnotetext{
${ }^{8}$ Alguns desses trabalhos já foram apresentados, de forma sintética, em artigos ou capítulos de livros (cf. VIEIRA, 2017b, 2018).

9 É preciso salientar que, em nosso entendimento, o suposto "uso do texto como pretexto" constitui um problema metodológico quando o material textual é aproveitado exclusivamente para trabalhar identificação de qualquer categoria, gramatical ou não. Além de toda a exploração do texto no plano macroestrutural, retirar fragmentos do texto (parágrafos, períodos, orações, sintagmas, palavras, morfemas, sílabas, grafemas) constitui relevante estratégia para o trabalho com o recurso gramatical, que, assim, pode ser observado também em contexto real, da língua em uso.
} 
de um lado, a sistematização do comportamento de variedades consoante o continuum compósito falaescrita e monitoração estilística; de outro lado, o desenvolvimento de metodologias para a abordagem das regras variáveis em sala de aula.

Quanto ao referido continuum, constitui agenda de pesquisa - já em curso - o mapeamento detalhado de uma variedade de fenômenos morfossintáticos em diversos gêneros da fala e da escrita contemporâneas, de modo a alcançar generalizações que permitam descrever melhor a distribuição das variantes nos espaços dessa linha imaginária. Em última instância, entende-se ser esse mapeamento fundamental para as reflexões que permitam cumprir o que propõe Faraco $(2015$, p. 8): "ter guias normativos que reflitam as normas efetivamente praticadas". Fica, assim, patente e clara a variabilidade interna ao que costumeiramente se chama "norma culta": um conjunto de usos variáveis em função de modalidade e de monitoração estilística. Ademais, os resultados obtidos também permitirão identificar, com objetividade, as variantes que, por serem improdutivas em gêneros da contemporaneidade ou serem empregadas apenas em contextos específicos, devem ser trabalhadas na esfera da recepção/escuta, e não na da produção textual.

No que se refere ao desenvolvimento de metodologias, as experiências com a proposta de ensino de gramática em três eixos (cf. VIEIRA, 2017a, 2017b, 2017c; 2018) têm demonstrado o êxito das atividades no sentido de contemplar a sistematicidade da variação e, ao mesmo tempo, a complexidade das regras variáveis no campo linguístico e extralinguístico. Nesse sentido, entende-se ser possível promover a ampliação do repertório dos alunos em termos de variação e normas, seja no âmbito da produção, seja no da recepção/leitura. Além disso, em termos de avaliação subjetiva das formas alternantes, será possível desenvolver a sensibilidade dos estudantes quanto ao valor social das variantes.

Para concluir e destacar o papel fundamental do professor de língua materna, no que se refere ao tratamento da variação lingüística (cf. BRANDÃO, 2007, p. 79; VIERA, 2009, p. 73), o que cabe ao professor de língua materna?

(a) respeitando o vernáculo do aluno, ensinar-lhe as diversas possibilidades do continuum da variação, no qual se enquadram inclusive variantes prestigiadas; (b) buscar estratégias que facilitem esse aprendizado (para reconhecimento ou emprego em gêneros textuais que o exijam), sem sugerir a substituição da variedade do aluno por outro; (c) levar o aluno a dominar os usos linguísticos compatíveis com gêneros (orais ou escritos) que exijam alto grau de formalidade e/ ou atendimento à determinada norma padrão. (VIEIRA, 2009, p. 73)

Dessa forma, entendemos que se inverte a direção: qualquer orientação pedagógica - normativa que seja - fica fundamentada na identidade da fala e da escrita brasileiras, em suas variedades cultas manifestas em gêneros diversos, e não em uma padronização externa, homogênea e ineficaz quanto a dar conta de nosso fazer diário, como leitores e produtores de textos.

\section{Referências}

ALMEIDA, S. C. M. de. Diagnose e análise de ordem dos clíticos pronominais em turmas de 90 ano: uma proposta interventiva. Rio de Janeiro, 2018. Dissertação (Mestrado Profissional em Letras/PROFLETRAS) - Faculdade de Letras, Universidade Federal do Rio de Janeiro. Rio de Janeiro, 2018. 
BORTONI-RICARDO, S. M. Um modelo para a análise sociolinguística do português brasileiro. In: Nós cheguemu na escola, e agora? Sociolingüística e Educação. São Paulo: Parábola Editorial, 2005. p. 39-52.

BRANDÃO, S. F. Concordância nominal. In: VIEIRA, S. R.; BRANDÃO, S. F. (Orgs.). Ensino de gramática: descrição e uso. São Paulo: Contexto, 2007. p. 58-73.

BRASIL. Ministério da Educação. Parâmetros Curriculares Nacionais: língua portuguesa. Brasília: MEC, 1998. Disponível em:<http://portal.mec.gov.br/seb/> Acesso em: 05 set. 2018.

BRASIL. Ministério da Educação. Base Nacional Comum Curricular. Proposta preliminar. Segunda versão revista. Brasília: MEC, 2016. Disponível em:< http://basenacionalcomum.mec.gov.br/>. Acesso em: 08 set. 2018.

CHAGAS, D. S. Concordância verbal de terceira pessoa: descrição sociolinguística e proposta pedagógica em turmas do ensino fundamental. 2016. Dissertação (Mestrado Profissional em Letras/PROFLETRAS) - Faculdade de Letras, Universidade Federal do Rio de Janeiro. Rio de Janeiro, 2016.

CYRANKA, L. Avaliação das variantes: atitudes e crenças em sala de aula. MARTINS, M.; VIEIRA, S.R; TAVARES, A (Orgs.). Ensino de Português e Sociolingüística. São Paulo: Contexto, 2014. p. 133-155.

DURVAL, L. F. da S. Uma experiência com o futuro do presente: reflexão linguística, variação e ensino. In: VIEIRA, S. R. (Org.). Gramática, variação e ensino: diagnose e propostas pedagógicas. Rio de Janeiro: Faculdade de Letras: UFR], 2017. [e-book]

FARACO, C. A. Norma culta brasileira - desatando alguns nós. São Paulo: Parábola Editorial, 2008.

FARACO, C. A. Norma culta brasileira: construção e ensino. In: ZILLES; A. M. S.; FARACO, C. A. (Orgs.). Pedagogia da variação linguística: língua, diversidade e ensino. São Paulo: Parábola, 2015. p. 19-30.

FARACO, C. A.; ZILLES, A. M. Para conhecer norma linguística. São Paulo: Contexto, 2017.

GAMA, D. E. R. S.; SARAIVA, E. S.; ALMEIDA; M. L. de. Tem variação entre as formas verbais impessoais ter e haver nas modalidades oral e escrita, em realizações da norma culta, do português brasileiro?. 2018. Monografia da disciplina Tópicos especiais (Programa de Pós-graduação em Letras Vernáculas) - Faculdade de Letras, Universidade Federal do Rio de Janeiro. Rio de Janeiro, 2018.

GOUVÊA, I. P. Variação das formas interlocutivas de segunda pessoa: estratégias pedagógicas. 2016. Dissertação (Mestrado Profissional em Letras/PROFLETRAS) - Faculdade de Letras, Universidade Federal do Rio de Janeiro. Rio de Janeiro, 2016.

LIMA, M. D; A. de O. Quadro de pronomes pessoais na escola: diagnose e proposta pedagógica. 2017. Dissertação (Mestrado em Letras Vernáculas) - Faculdade de Letras, Universidade Federal do Rio de Janeiro. Rio de Janeiro, 2017.

MARTINS, M. A.; ABRAÇADO, J. (Orgs.). Mapeamento sociolinguístico do Português Brasileiro. São Paulo: Contexto, 2014

MARTINS, M.; VIEIRA, S.R; TAVARES, A (Orgs.). Ensino de Português e Sociolinguística. São Paulo: Contexto, 2014

SOUZA, D. da S. Estratégias de indeterminação do sujeito: uma proposta pedagógica para o ensino de gramática. 2015. Dissertação (Mestrado Profissional em Letras/PROFLETRAS) - Faculdade de Letras, Universidade Federal do Rio de Janeiro. Rio de Janeiro, 2015.

VIEIRA, S. R. Variação lingüística, texto e ensino. Revista CON(TEXTOS) Linguísticos. Vitória, n. 3, p. 53-75, set. 2009.

VIEIRA, S. R. Sociolinguística e ensino de português: para uma pedagogia da variação linguística. In: MARTINS, M. A., TAVARES, M. A. (Orgs.). Contribuições da Sociolinguística e da Linguística Histórica para o ensino de língua portuguesa. Coleção Ciências da Linguagem Aplicadas ao Ensino, volume V. Natal: EDUFRN, 2013. p. 53-90.

VIEIRA, S. R. Variação estilística e ordem dos clíticos pronominais: a influência dos gêneros textuais e dos veículos jornalísticos GORSKI, E. M.; COELHO, I. L.; SOUZA, C. M. N. de. (Orgs.). Variação estilística: reflexões teórico-metodológicas e propostas de análise. Florianópolis: Insular, 2014. p. 281-301.

VIEIRA, S. R. Três eixos para o ensino de gramática: uma proposta experimental. In: NORONHA, C. A.; SÁ JR., L. A. de. (Orgs.). Escola, ensino e linguagem. Natal-RN, EDUFRN, 2017a. Disponível em:<https://repositorio.ufrn.br>.

VIEIRA, S. R. Três eixos para o ensino de gramática. In: Vieira, S. R. (Org.). Gramática, variação e ensino: diagnose \& propostas pedagógicas. Rio de Janeiro: Letras UFRJ, 2017b. p. 68-82. Disponível em:<http://www.letras.ufrj.br/posverna>.

VIEIRA, S. R. Prática de análise linguística sem ensino de gramática? In: ATAÍDE, C. et alii. (Orgs.). Gelne 40 anos: experiências teóricas e práticas nas pesquisas em linguística e literatura. São Paulo: Blucher, 2017c. p. 299-318. 
Disponível em:<https://www.blucher.com.br/>

VIEIRA, S. R. Ensino de português e o contínuo fala-escrita: o caso das estratégias de relativização. Revista PerCursos, Florianópolis, v. 18, n. 37, p. 08 - 35, mai./ago. 2017d.

VIEIRA, S. R. (Org.) Gramática, variação e ensino: diagnose e propostas pedagógicas. 2. ed. rev. e ampl. São Paulo: Blucher, 2018. Disponível em:<https://www.blucher.com.br/>

VIEIRA, S. R.; BRANDÃO, S. F. (Orgs.). Ensino de gramática: descrição e uso. São Paulo: Contexto, 2007.

VIEIRA, S. R.; FREIRE, G. Variação morfossintática e ensino de Português. In: MARTINS, M.; VIEIRA, S.R; TAVARES, A (Orgs.). Ensino de Português e Sociolinguística. São Paulo: Contexto, 2014. p. 81-114.

ZILLES; A. M. S.; FARACO, C. A. (Orgs.). Pedagogia da variação linguística: língua, diversidade e ensino. São Paulo: Parábola, 2015. 